\title{
Synthesis, characterization and electro-catalytic properties of a water-soluble nickel(II) complex supported by picolinic acid ions
}

\author{
Dan Xue, Qiu-Xia Peng, Dong Li, Shu-Zhong Zhan* \\ College of Chemistry \& Chemical Engineering, South China University of \\ Technology, Guangzhou 510640, China
}

\begin{abstract}
The reaction of picolinic acid (HA) with $\mathrm{NiCl}_{2} \cdot 6 \mathrm{H}_{2} \mathrm{~A}$ affords a nickel(II) complex, $\left[\mathrm{NiA}_{2}\left(\mathrm{H}_{2} \mathrm{O}\right)_{2}\right] \mathbf{1}$ (A: picolinic acid ion), which has been characterized by using physics-chemical and spectroscopic methods. Electrochemical investigations shows that $\mathbf{1}$ can act as a homogeneous electrocatalyst for water reduction in a purely aqueous medium. 1 catalyses hydrogen evolution from a neutral water ( $\mathrm{pH} 7.0)$ with a turnover frequency (TOF) of 568 moles of hydrogen per mole of catalyst per hour at an overpotential (OP) of $687.6 \mathrm{mV}$. To prove that the combination of nickel center and picolinic ion is the key structural feature for eliciting proton or water reduction catalysis, we also investigate the electro-catalytic activities of $\left[\mathrm{NiA}_{2}\left(\mathrm{H}_{2} \mathrm{O}\right)_{2}\right] \mathbf{1}$ and $\mathrm{Ni}(\mathrm{Ac})_{2} \cdot 2 \mathrm{H}_{2} \mathrm{O}$ and provide a possible catalytic mechanism for hydrogen generation by this nickel complex. The result also exhibits that nickel center constitutes the better active catalyst than the cobalt sample with same ligands.
\end{abstract}

Keywords: Nickel(II) complex; molecular electrocatalyst; proton or water reduction; hydrogen generation. 
* Corresponding author. Fax: +86-20-87112053.

E-mail address: shzhzhan@scut.edu.cn (S.-Z. Zhan).

\section{Introduction}

To avoid energy crisis and reduce environmental pollution, people are developing new systems for new energy sources. And hydrogen is one of the most ideal energy in the future, because of its numerous advantages such as recyclability and pollution-free use [1]. Water is the only waste-free electron-source substrate that could sustain the scale of the process required to supply our energy demands. Thus splitting water is an important and simple method for hydrogen production in high purity and large quantities [2]. Among current technologies for hydrogen production, electrocatalytic water reduction via hydrogen evolution reaction (HER) is considered as one of the most attractive and simple methods [3]. So far, many research groups, including ours, have developed several molecular catalysts for hydrogen generation from organic acid and water based on transition metal complexes, such as nickel [4-13], cobalt [14-17], copper [18,19], iron [20] and manganese [21]. Despite much progress in water reduction catalysis, major improvements in several areas, including decreasing structural complexity and increasing solubility in aqueous media, are needed before efficient electrocatalytic water reduction can be realized [22]. Our works focus on the design of molecular electrocatalysts that are water soluble and can efficiently catalyze water reduction. In this paper, we present the synthesis, characterization and catalytic properties of the complex, $\left[\mathrm{NiA}_{2}\left(\mathrm{H}_{2} \mathrm{O}\right)_{2}\right] \mathbf{1}$, as well as 
the effect of the metal centers on the electrocatalytic activity. We hope this can afford a method for the improvement in electrocatalytic hydrogen production by the structural modification of complexes.

\section{Experimental section}

\subsection{Physical measurements}

Elemental analyses for $\mathrm{C}, \mathrm{H}$, and $\mathrm{N}$ were obtained on a Perkin-Elmer analyzer model 240. UV-Vis spectra were measured on a Hitachi U-3010 spectrometer. ESI-MS experiment was performed on a Bruker Daltonics Esquire 3000 spectrometer by introducing samples directly into the ESI source using a syringe pump. Thermogravimetric (TG) analysis was carried out using a Universal V4 4A Intruments with a heating rate $10^{\circ} \mathrm{C} / \mathrm{min}$ in flowing air. Cyclic voltammograms were obtained on a CHI-660E electrochemical analyzer under $\mathrm{N}_{2}$ using a three-electrode cell in which a glassy carbon electrode was the working electrode, a saturated $\mathrm{Ag} / \mathrm{AgCl}$ electrode was the reference electrode, and platinum wire was the auxiliary electrode. Controlled-potential electrolysis (CPE) in organic and aqueous media were conducted by using the literature procedure [23]. Gas chromatograph (GC) experiments were carried out with an Agilent Technologies 7890A gas chromatography instrument.

\subsection{Synthesis of complex $\left[\mathrm{NiA}_{2}\left(\mathrm{H}_{2} \mathrm{O}\right)_{2}\right] \cdot 2 \mathrm{H}_{2} \mathrm{O}, \mathrm{1} \cdot 2 \mathrm{H}_{2} \mathrm{O}$}

To a solution of $\mathrm{NiCl}_{2} \cdot 6 \mathrm{H}_{2} \mathrm{O}(0.238 \mathrm{~g}, 1 \mathrm{mmol})$ in methanol $(10 \mathrm{ml})$, picolinic 
acid $(0.246 \mathrm{~g}, 2 \mathrm{mmol})$ in methanol $(10 \mathrm{ml})$ was added and the mixture was stirred for 30 min. Standing at room temperature for several days gave green crystals, which were collected by filtration, and dried in vacuo $(0.17 \mathrm{~g}, 45 \%)$. The elemental analysis results (Found $\mathrm{C}, 38.24 ; \mathrm{H}, 4.27 ; \mathrm{N}, 7.48 . \mathrm{C}_{12} \mathrm{H}_{16} \mathrm{NiN}_{2} \mathrm{O}_{8}$ requires $\mathrm{C}, 38.44 ; \mathrm{H}, 4.3 ; \mathrm{N}$, 7.47) were in agreement with the formula of the sample used for X-ray analysis.

\subsection{Crystal structure determination}

The X-ray analysis of $\mathbf{1}$ was carried out with a Bruker Smart Apex II DUO area detector using graphite monochromated Mo-K $\alpha$ radiation $(\lambda=0.71073 \AA)$ at room temperature. All empirical absorption corrections were applied by using the SADABS program [24]. The structure was solved using direct methods and the corresponding non-hydrogen atoms are refined anisotropically. All the hydrogen atoms of the ligands were placed in calculated positions with fixed isotropic thermal parameters and included in the structure factor calculations in the final stage of full-matrix least-squares refinement. All calculations were performed using the SHELXTL-97 computer program [25]. Crystallographic data for complex $\mathbf{1}$ are given in Table S1 and selected bond lengths and angles are listed in Table S2. CCDC 1521729 contains the supplementary crystallographic data for this paper. This data can be obtained free of charge via http://www.ccdc.cam.ac.uk/conts/retrieving.html.

\section{Results and discussion}

\subsection{Structural analysis and general characterization}


The reaction of picolinic acid (HA) and $\mathrm{NiCl}_{2} \cdot 6 \mathrm{H}_{2} \mathrm{O}$ forms one nickel(II) complex, $\left[\mathrm{Ni}(\mathrm{A})_{2}\left(\mathrm{H}_{2} \mathrm{O}\right)_{2}\right] \mathbf{1}$ (Scheme 1), which is soluble both in water and several organic solvents. As shown in Fig. S1, complex 1 exhibits an absorption band at about $264 \mathrm{~nm}$, which corresponds to a pi-pi* transition of the $\mathrm{A}^{-}$moiety. From Figs. S2-3, in the $\mathrm{pH}$ range 2.0 to 12.0 , the intensity of the absorption band at $264 \mathrm{~nm}$ decreases, suggesting new components are being formed. These observations point to the formation of dinuclear or polynuclear species [14].

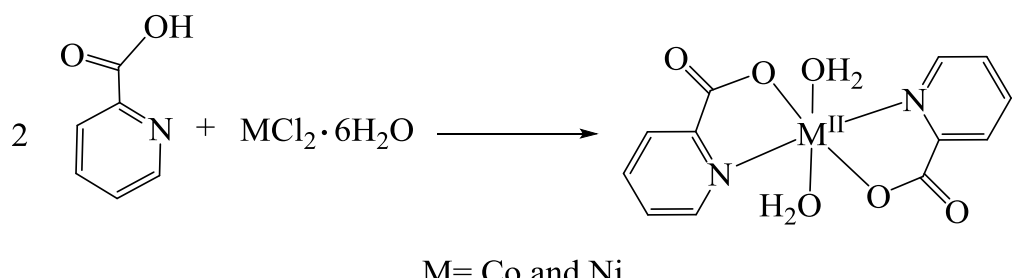

Scheme 1 Synthesis of complexes, $\left[\mathrm{M}(\mathrm{A})_{2}\left(\mathrm{H}_{2} \mathrm{O}\right)_{2}\right](\mathrm{M}=\mathrm{Co}$ and $\mathrm{Ni})$

According to Fig. 1, in solid, complex $\mathbf{1}$ is formed by one $\mathrm{Ni}^{2+}$ ion, two picolinic acid ions, and two $\mathrm{H}_{2} \mathrm{O}$ molecules. The nickel atom is six-coordinated by two nitrogen atoms, two oxygen atoms from picolinic acid ions, and two oxygen atoms from two $\mathrm{H}_{2} \mathrm{O}$ molecules. The Ni-N distance is 2.0661(16) $\AA$. And the bond distance of Ni and $\mathrm{O}$ from picolinic acid $\left(2.0492(13) \AA\right.$ ) is shorter than that of $\mathrm{Ni}$ and $\mathrm{O}$ from $\mathrm{H}_{2} \mathrm{O}$ (2.0980(13) A). To prove that the different length of Ni-O bonds can affect the forms in solution, ESI-MS measurement for complex 1 was conducted in methanol. As shown in Fig. S4, the electrospray mass spectrum of $\mathbf{1}$ exhibits one ion at a mass-to-charge ratio $(\mathrm{m} / \mathrm{z})$ of 342.9835 , with mass and isotope distribution pattern corresponding to $\left[\mathrm{Ni}(\mathrm{A})_{2}\left(\mathrm{H}_{2} \mathrm{O}\right) \mathrm{Na}\right]^{+}$, indicating that one coordinated $\mathrm{H}_{2} \mathrm{O}$ dissociates 
from nickel center in methanol.

\subsection{Thermal decomposition process for complex 1}

In order to check the stability of complex $\mathbf{1}$ in solid, TG curve of complex $\mathbf{1}$ was measured in the temperature range $50-250{ }^{\circ} \mathrm{C}$. According to Fig. 2, with increasing temperature, complex 1 exhibits marked mass losses in two steps. The first TG weight loss of approximately $9.70 \%$ in the temperature range $50-129.3{ }^{\circ} \mathrm{C}$ with an endothermic peak at $129.3{ }^{\circ} \mathrm{C}$ is mainly due to the departure of two lattice water molecules from complex 1 (theoretical weight loss 9.60\%). The subsequent thermal decomposition of complex 1 , with a mass loss of $9.60 \%$ in the range $140-203{ }^{\circ} \mathrm{C}$, is contributed to the departure of two coordination water molecules (theoretical weight loss $9.60 \%$ ), indicating the combination of nickel atom with water molecules is weak. This result is agreement with the above ESI-MS analysis. When the temperature increases further, no significant weight loss was observed for $\mathbf{1}$.

\subsection{Linear scan voltammetry}

Based on that nickel complexes can electrocatalyze hydrogen generation both from acetic acid or aqueous buffer via an unstable hydride intermediate [6,26], we tried to test if this nickel complex also can act as an electrocatalyst for hydrogen evolution. To study the electrochemical behavior of the complex, first we used linear scan voltammetry (LSV) to investigate the reduction of water at the glassy carbon electrode surface with or without complex 1. As shown in Fig. 3, the onset of water 
reduction moves to more anodic values with the sequential increments of complex $\mathbf{1}$ concentration. Moreover, the catalytic current increases significantly with decrease of pH values from 7.0 to 3.5 (Fig. S5), suggesting that there is a protonation step in the catalytic reaction.

\subsection{Cyclic voltammetry}

Flowingly, we tested its electrochemical properties by using cyclic voltammetry. With $0.10 \mathrm{M}\left[(\mathrm{n}-\mathrm{Bu})_{4} \mathrm{~N}\right] \mathrm{ClO}_{4}$ as the supporting electrolyte in $\mathrm{CH}_{3} \mathrm{CN}$ at a glassy carbon electrode, complex 1 displayed one reversible redox couple at $-1.41 \mathrm{~V}$ versus $\mathrm{Ag} / \mathrm{AgNO}_{3}$, which can be assigned to the $\mathrm{Ni}^{\mathrm{II} / \mathrm{I}}$ couple (Fig. 4). To further get the information of this nickel complex, cyclic voltammograms (CVs) were recorded at varying scan rates. According to Fig. S6, the current responses of the redox event at $-1.58 \mathrm{~V}$ shows a linear dependence on the square root of the scan rate, which is an indicative of a diffusion-controlled process in the solution.

\subsection{Electrocatalytic hydrogen generation from acetic acid in $\mathrm{CH}_{3} \mathrm{CN}$}

To check catalytic activity of complex 1, we chosen acetic acid as proton resource. From Fig. 5, with the sequential increments of acetic acid concentration (from 0.00 to $5.00 \mathrm{mM}$ ), the current strength near $-1.58 \mathrm{~V}$ versus $\mathrm{Ag} / \mathrm{AgNO}_{3}$ increased markedly, which can be assigned to the catalytic generation of $\mathrm{H}_{2}$ from acetic acid [27]. The result shows that $\mathrm{H}_{2}$ production electrocatalyzed by complex $\mathbf{1}$ requires the reduction potential of $\mathrm{Ni}(\mathrm{II})$ to $\mathrm{Ni}(\mathrm{I})$. On the basis of literature precedent [26], ESI-MS and above analyses, a possible mechanism for electro-catalyst of complex $\mathbf{1}$ 
can be presented in Scheme 2. According to Scheme 2, one-electron reduction of $\left[\mathrm{A}_{2} \mathrm{Ni}^{\mathrm{II}}\left(\mathrm{H}_{2} \mathrm{O}\right)_{2}\right] 1$ gives a putative $\left[\mathrm{A}_{2} \mathrm{Ni}^{\mathrm{I}}\left(\mathrm{H}_{2} \mathrm{O}\right)\right]^{-}$species via losing one water molecule. Addition of hydrogen proton yields the $\mathrm{Ni}^{\mathrm{III}}-\mathrm{H}$ species, a high reactive intermediate. Further addition of hydrogen proton of the $\mathrm{Ni}^{\mathrm{III}}$-H species affords $\mathrm{H}_{2}$, and regenerates the starting complex $\mathbf{1}$.
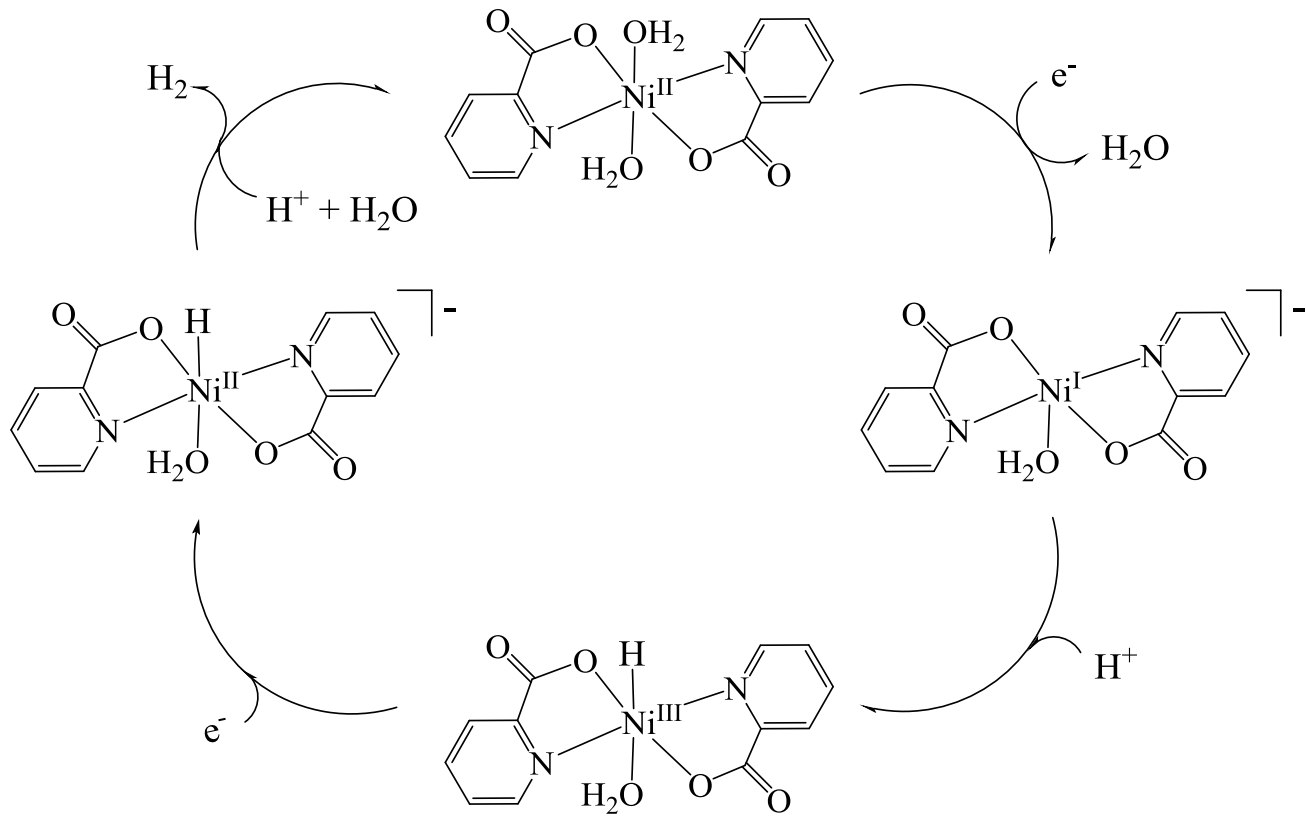

Scheme 2 The possible catalytic mechanism for proton reduction by complex $\mathbf{1}$

The above catalytic system was further characterized by bulk electrolysis from $5.34 \mu \mathrm{M}$ complex 1 with acetic acid in $\mathrm{CH}_{3} \mathrm{CN}$ under variable applied potential. As shown in Fig. S7a, when the applied potential was $-1.45 \mathrm{~V}$ versus $\mathrm{Ag} / \mathrm{AgNO}_{3}$, the maximum charge reached $91 \mathrm{mC}$ used $2 \mathrm{~min}$. Whilst a controlled-potential electrolysis (CPE) experiment under the same potential but without complex 1 gave a charge of only $3 \mathrm{mC}$ (Fig. S7b), suggesting that this complex does indeed serve as effective hydrogen producer under such conditions. Using Equations (1) [28] and (2) 
[29], the TOF was estimated to be 52 moles of hydrogen per mole of catalyst per hour at an OP of $941.6 \mathrm{mV}$ (Eq. S1 and Fig. S8). Remarkably, complex 1 is more effective than that of $\left[\mathrm{CoA}_{2}\left(\mathrm{H}_{2} \mathrm{O}\right)_{2}\right](42.1 \mathrm{~mol}$ of hydrogen per mole of catalyst per hour at an OP of $941.6 \mathrm{mV}$ ) [30], showing that nickel center constitutes the better active catalyst than the cobalt sample with picolinic acid ions.

$\mathrm{TOF}=\Delta C /\left(\mathrm{F}^{*} n_{1} * n_{2} * t\right)$

Overpotential $=$ Applied potential $-\mathrm{E}^{\odot} \mathrm{HA}$

$$
=\text { Applied potential }-\left(\mathrm{E}^{\odot}{ }_{\mathrm{H}}{ }^{+}-(2.303 R T / F) \mathrm{p} K_{a \mathrm{HA}}\right)
$$

Where, $\Delta C$ is the charge from the catalyst solution during CPE minus the charge from solution without catalyst during CPE; $\mathrm{F}$ is Faraday's constant, $n_{1}$ is the number of moles of electrons required to generate one mole of $\mathrm{H}_{2}, n_{2}$ is the number of moles of catalyst in solution, and $\mathrm{t}$ is the duration of electrolysis.

\subsection{Electrocatalytic hydrogen evolution from aqueous buffer}

We then explored the electrocatalytic behavior of complex $\mathbf{1}$ in aqueous media. As shown in Fig. S9, the current strength increased with increasing concentrations of complex 1 from 0.00 to $1.60 \mu \mathrm{M}$. To further probe the nature of this reduction process, we investigated the $\mathrm{pH}$ dependence of the cathodic peak potential. According to Fig. $\mathrm{S} 10$, the current strength increased significantly under lower $\mathrm{pH}$ values, which is consist with a electrocatalytic process, showing $\mathbf{1}$ can catalyze water reduction to form $\mathrm{H}_{2}[31]$.

To further obtain the evidence for the activity in aqueous media, the bulk 
electrolysis from a $7.14 \mu \mathrm{M}$ complex 1 was conducted in a neutral buffer under variable applied potentials. When an applied potential was $-1.45 \mathrm{~V}$ versus $\mathrm{Ag} / \mathrm{AgCl}$, the maximum charge was $32 \mathrm{mC}$ over 2 min without complex 1 (Fig. 6a). Under the same conditions, the charge reached $1144 \mathrm{mC}$ with addition of complex 1 (Fig. 6b), accompanied by the appearance of gas bubbles which was confirmed to be $\mathrm{H}_{2}$ by GC analysis. According to Fig. S11, $\sim 17 \mathrm{~mL}$ of $\mathrm{H}_{2}$ was obtained over an electrolysis period of $1 \mathrm{~h}$ with a Faradaic efficiency of $91.67 \%$ for dihydrogen (Fig. S12). Using Equations (1) and (3) [32], the TOF was calculated to be 646.31 moles of hydrogen per mole of catalyst per hour at an OP of $837.6 \mathrm{mV}$ (Eq. S2 and Fig. S13).

Overpotential $=$ Applied potential $-\mathrm{E}(\mathrm{pH})=$ Applied potential- $(-0.059 \mathrm{pH})$

To further prove that complex $\mathbf{1}$ is indeed responsible for the electrocatalytic $\mathrm{H}_{2}$ generation in the above system, several control experiments were carried out. For example, HA, aqueous buffer solution, and $\mathrm{Ni}(\mathrm{Ac})_{2} \cdot \mathrm{H}_{2} \mathrm{O}$ were each measured under identical conditions. As shown in Fig. 7, a neutral buffer solution only affords 31 of charge during 2 min of electrolysis under $-1.45 \mathrm{~V}$ versus $\mathrm{Ag} / \mathrm{AgCl}$. The use of solely HA or $\mathrm{Ni}(\mathrm{Ac})_{2} \cdot 2 \mathrm{H}_{2} \mathrm{O}$ as a catalyst affords $\mathrm{H}_{2}$ with $55 \mathrm{mC}$ and $257 \mathrm{mC}$ of charge, respectively. However, when complex $\mathbf{1}$ is employed as the catalyst, bulk electrolysis provides $\mathrm{H}_{2}$ with $1272 \mathrm{mC}$ of charge. Thus, the combination of nickel ion with $\mathrm{A}^{-}$is essential for catalytic activity in above electrocatalytic system.

From Fig. S13, the TOF of 646.31 moles of hydrogen per mole of catalyst per hour at an OP of $0.838 \mathrm{~V}$ produced by complex $\mathbf{1}$ is higher than that of other molecular nickel catalysts reported in the literature for electrochemical hydrogen 
production from a neutral water. For instance, a dinickel complex supported by macrocyclic ligand that exhibits a TOF of 160 moles of $\mathrm{H}_{2}$ per mole of catalyst per hour at an OP of $820 \mathrm{mV}$ [33], a nickel complex with 2,3-bis(2-hydroxybenzylideneimino)-2,3-butenedinitrile ion that achieves a TOF of 436 moles of $\mathrm{H}_{2}$ per mole of catalyst per hour at an $\mathrm{OP}$ of $837.6 \mathrm{mV}$ [6], and $\left[\mathrm{Ni}(\mathrm{mnt})_{2}\right]^{2-}(\mathrm{mnt}=2,2$-dicyanoethylene-1,1-dithiolate $)$ that shows a TOF of 282 moles of hydrogen per mole of catalyst per hour at an OP of $0.848 \mathrm{~V}$ [34].

In term of TOF, under similar conditions, the electro-catalytic activity of complex 1 (Fig. S13, $568 \mathrm{~mol}$ of $\mathrm{H}_{2}$ per mole of catalyst per hour at an OP of 687.6 $\mathrm{mV}$ ) is higher than a cobalt complex supported by identical ligands that shows a TOF of $343 \mathrm{~mol}$ of $\mathrm{H}_{2}$ per mole of catalyst per hour at an $\mathrm{OP}$ of $687.6 \mathrm{mV}$ [30]. The result is in agreement with our previous investigation that a nickel complex could constitute more active electrocatalytic system than that of cobalt sample with identical ligands [26]. And further studies are under investigation.

\subsection{Investigation of the stability and durability of complex 1}

In order to determine whether 1 retains activity over longer time periods, a $72 \mathrm{~h}$ $\mathrm{CPE}$ at $-1.45 \mathrm{~V}$ versus $\mathrm{Ag} / \mathrm{AgCl}$ was conducted in a neutral buffer containing 5.34 $\mu \mathrm{M}$ complex 1. According to Fig. S14, the catalyst affords a charge build-up over time, with no substantial loss in activity used 72 hours, and a total of $739 \mathrm{C}$ is passed during the electrolysis. 


\section{Conclusion}

One six-coordinated complex $\mathbf{1}$ was synthesized by a facile procedure and exhibited apparent catalytic activity in electrochemical proton or water reduction. In liquid, the unoccupied positions in axial direction of complex $\mathbf{1}$ is the key structural feature for eliciting proton or water reduction catalysis. This discovery has established a new chemical paradigm for creating water reduction catalysts with simple structures that are highly active in purely aqueous media.

\section{Acknowledgements}

This work was supported by the National Science Foundation of China (No. 20971045 and 21271073).

\section{References}

[1] M. G. Walter, E. L. Warren, J. R. McKone, S. W. Boettcher, Q. X. Mi, E. A. Santori, N. S. Lewis, Chem. Rev. 110 (2010) 6446 - 6473.

[2] H. M. Chen, C. K. Chen, R. S. Liu, L. Zhang, J. J. Zhang, D. P. Wilkinson, Chem. Soc. Rev. 41 (2012) 5654-5671.

[3] A. Thapper, S. R. Styring, G. Saracco, A. W. Rutherford, B. Robert, A. Magnuson, W. Lubitz, A. Llobet, P. Kurz, A. Holzwarth, S. Fiechter, H. de Groot, S. Campagna, A. Braun, H. Bercegol, V. Artero, Green 3 (2013) 43-57.

[4] M. L. Helm, M. P. Stewart, R. M. Bullock, M. R. DuBois, D. L. DuBois, Science 333 (2011) 863-866.

[5] A. Manuela, M. A. Gross, A. Reynal, J. R. Durrant, E. Reisner, J. Am. Chem. Soc. 
136 (2014) 356-366.

[6] J. P. Cao, T. Fang, L. Z. Fu, L. L. Zhou, S. Z. Zhan, Int. J. Hydrogen Energy 39 (2014) 10980-10986.

[7] L. Chen, G. Chen, C.-F. Leung, S.-M. Yiu, C.-C. Ko, E. Anxolabéhère-Mallart, M. Robert, T.-C. Lau, ACS Catal. 5 (2015) 356-364.

[8] A. Das, Z. Han, W. W. Brennessel, P. L. Holland, R. Eisenberg, ACS Catal. 5 (2015) 1397-1406.

[9] L. Gan, T. L. Groy, P. Tarakeshwar, S. K. S. Mazinani, J. Shearer, V. Mujica, A. K. Jones, J. Am. Chem. Soc. 137 (2015) 1109-1115.

[10] D. Xue, Q. Y. Lv, C. N. Lin, S. Z. Zhan. Polyhedron 117 (2016) 300-3008.

[11] Tsay, C.; Yang, J. Y. J. Am. Chem. Soc. 138 (2016) 14174-14177.

[12] Rountree, E. S.; Dempsey, J. L. Inorg. Chem. 55 (2016) 5079-5087.

[13] R.Tatematsu, T. Inomata, T. Ozawa, H. Masuda, Angew. Chem. Int. Ed. 55 (2016) 5247-5250.

[14] L. Tong, R. Zong, R. P. Thummel, J. Am. Chem. Soc. 136 (2014) 4881-4884.

[15] L. Z. Fu, L. L. Zhou, L. Z. Tang, Y. X. Zhang, S. Z. Zhan, J. Power Sources 280 (2015) 453-458.

[16] A. Rodenberg, M. Orazietti, B. Probst, C. Bachmann, R. Alberto, K. K. Baldridge, Inorg. Chem. 54 (2015) 646-657.

[17] B. Kandemir, L. Kubie, Y. Guo, B. Sheldon, K. L. Bren, Inorg. Chem. 55 (2016) $1355-1357$. 
[18] T. Fang, L. Z. Fu, L. L. Zhou, S. Z. Zhan, Electrochimica Acta 161 (2015) 388-394.

[19] L. L. Zhou, T. Fang, J. P. Cao, Z. Zhu, X. Su, S. Z. Zhan, J. Power Sources 273 (2015) 298-304.

[20] F. Gloaguen, Inorg. Chem. 55 (2016) 390-398.

[21] M. D. Sampson, C. P. Kubiak, Inorg. Chem. 54 (2015) 6674-6676.

[22] C. C. L. McCrory, C. Uyeda, J. C. Peters, J. Am. Chem. Soc. 134 (2012) 3164-3170.

[23] L. L. Zhou, L. Z. Fu, L. Z. Tang, Y. X. Zhang, S. Z. Zhan, Int. J. Hydrogen Energy 40 (2015) 5099-5105.

[24] Sheldrick GM, SADABS, Program for Empirical Absorption Correction of Area Detector Data, University of Götingen, Götingen, Germany, 1996.

[25] Sheldrick GM, SHELXS 97, Program for Crystal Structure Refinement, University of Götingen, Götingen, Germany, 1997.

[26] Y.-X. Zhang, L.-Z. Tang, Y.-F. Deng, S.-Z. Zhan, Inorg. Chem. Commun. 72 (2016) 100-104.

[27] H. I. Karunadasa, C. J. Chang, J. R. Long, Nature 464 (2010) 1329-1333.

[28] L. Tong, R. Zong, R. P. Thummel, J. Am. Chem. Soc. 136 (2014) 4881-4884.

[29] G. A. N. Felton, R. S. Glass, D. L. Lichtenberger, D. H. Evans, Inorg. Chem. 45 (2006) $9181-9184$.

[30] L.-Z. Fu, L.-Z. Tang, Y.-X. Zhang, Q.-N. Liang, C. Fang, S.-Z. Zhan, Int. J. Hydrogen Energy 41 (2016) 249-254. 
[31] R. S. Nichloson, I. Shain, Anal. Chem. 36 (1964) 706-723.

[32] Y. Sun, J. P. Bigi, N. A. Piro, M. L. Tang, J. R. Long, C. J. Chang, J. Am. Chem. Soc. 133 (2011) 9212-9215.

[33] J. P. Collin, A. Jouaiti, J. P. Sauvage, Inorg. Chem. 27 (1988) 1986-1990.

[34] C.-N. Lin, D. Xue, Y.-H. Zhou, S.-Z. Zhan, C.-L. Ni, J. Electroanal. Chem. 785 (2017) 58-64. 


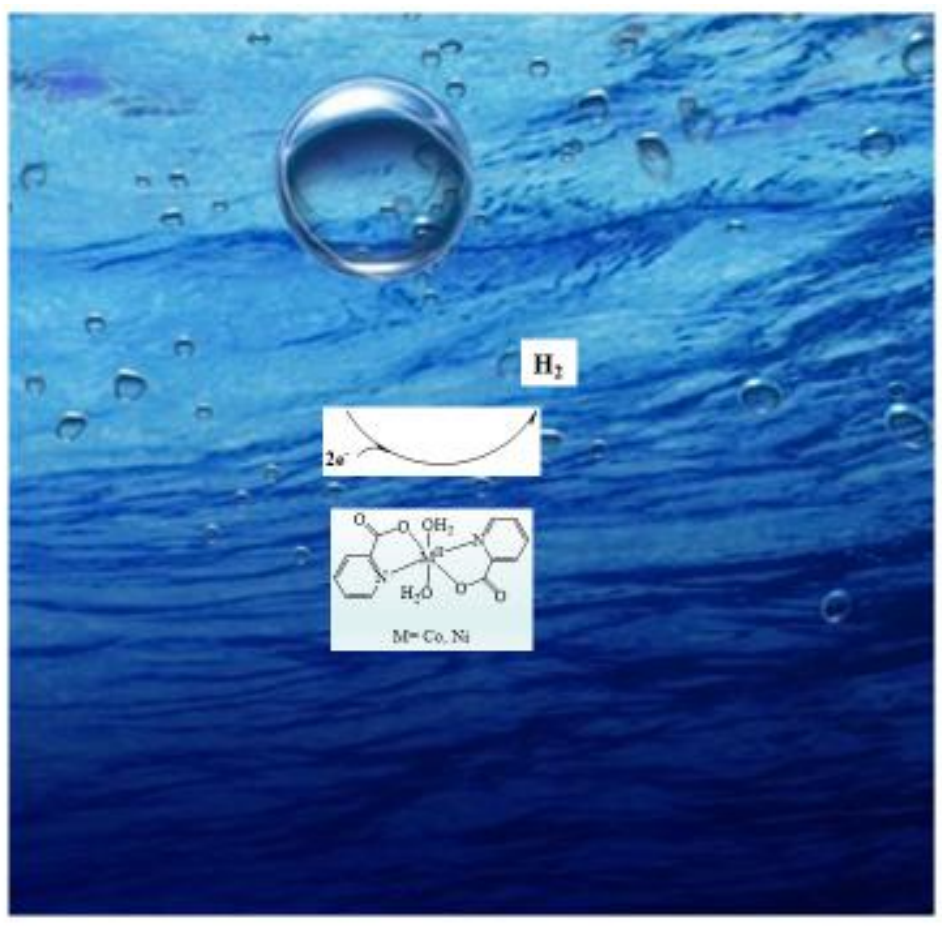




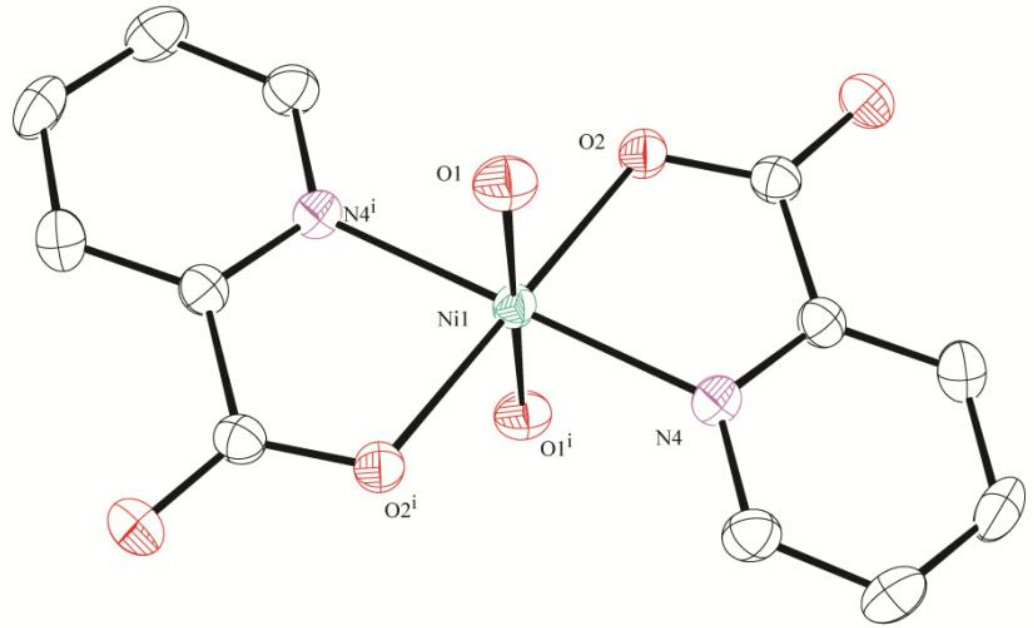

Fig. 1. ORTEP drawing of complex 1 with thermal ellipsoids on the 50\% probability level (hydrogen atoms are not shown). 


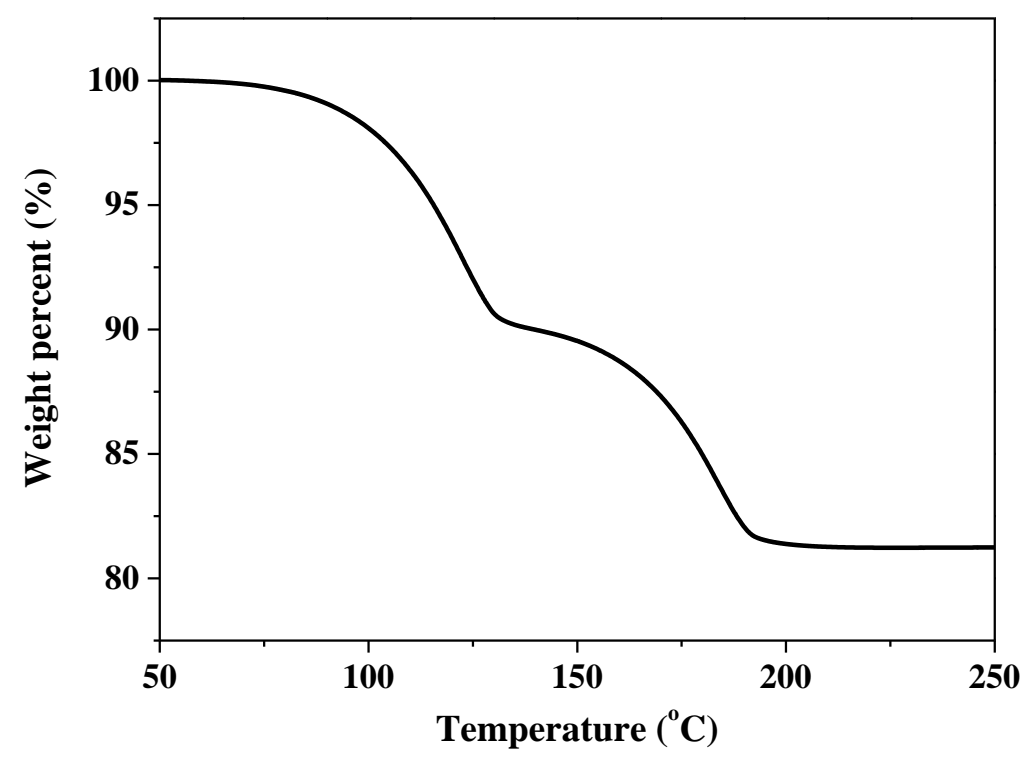

Fig. 2. The TG curve of complex 1. 


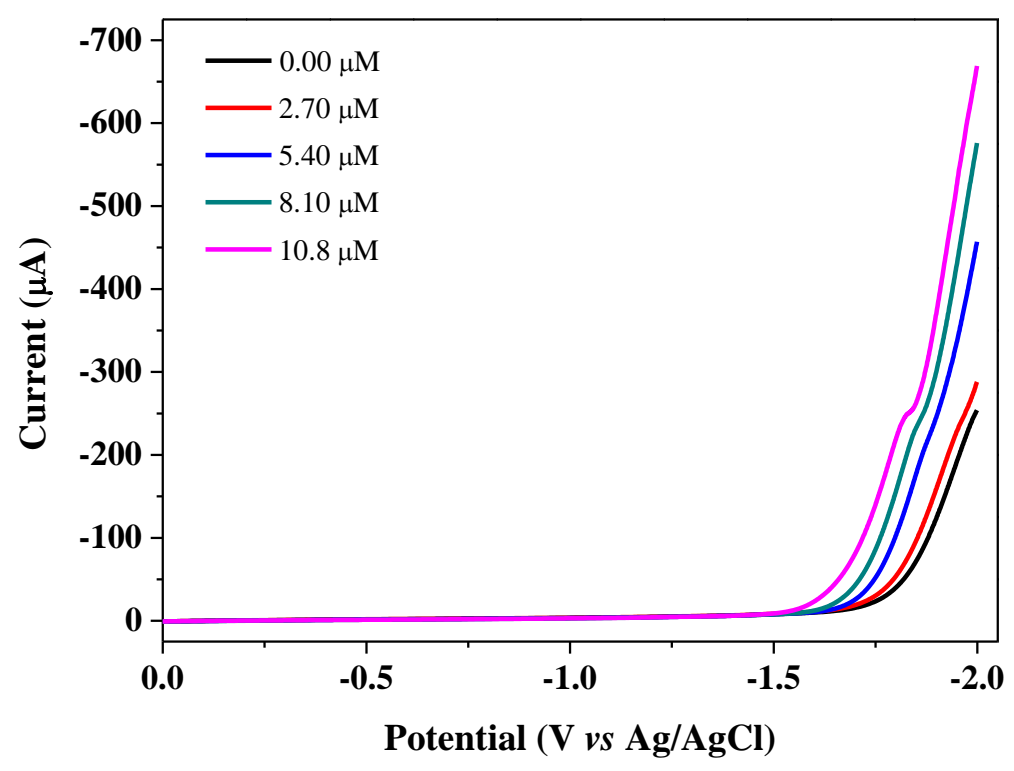

Fig. 3. Linear sweep voltammogram of complex $\mathbf{l}$ with varying concentrations. Conditions: $0.25 \mathrm{M}$ buffered solution ( $\mathrm{pH}$ 7.0), glassy carbon working electrode (1 $\mathrm{mm}$ diameter), $\mathrm{Pt}$ wire counter electrode, $\mathrm{Ag} / \mathrm{AgCl}$ reference electrode. 


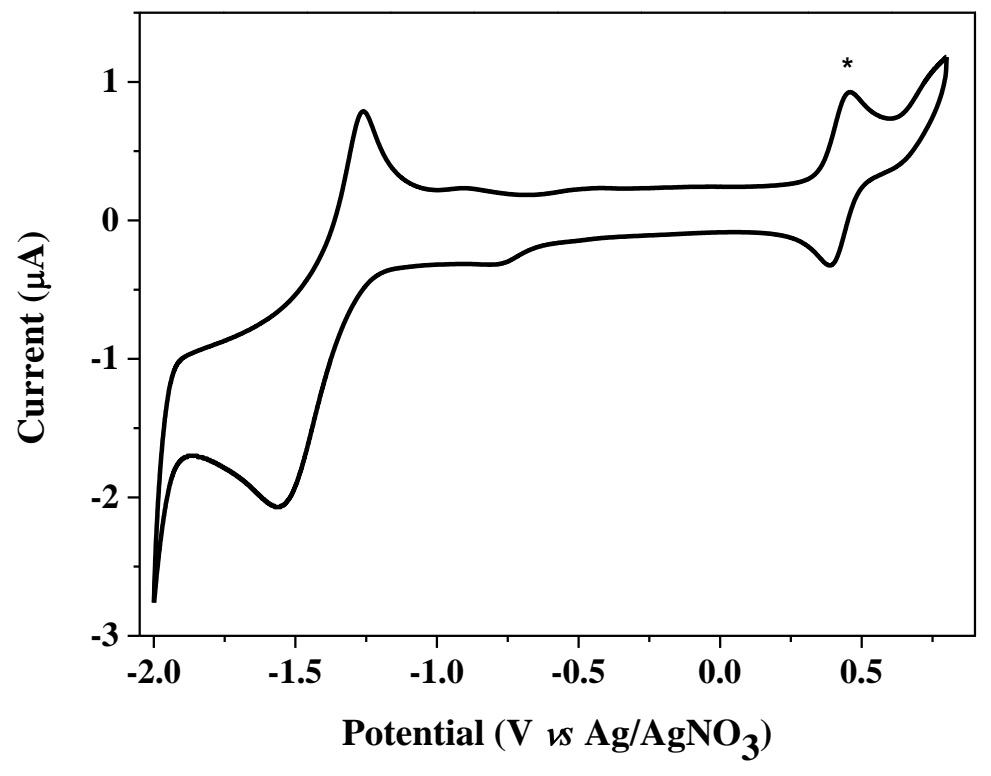

Fig. 4. Cyclic voltammogram (CV) of $2.94 \mathrm{mM}$ complex 1 in $0.10 \mathrm{M}$ of $\left[\mathrm{n}-\mathrm{Bu}_{4} \mathrm{~N}\right] \mathrm{ClO}_{4} \mathrm{CH}_{3} \mathrm{CN}$ solution at a glassy carbon electrode and a scan rate of 50 $\mathrm{mV} / \mathrm{s}$. Fc internal standard (*). 


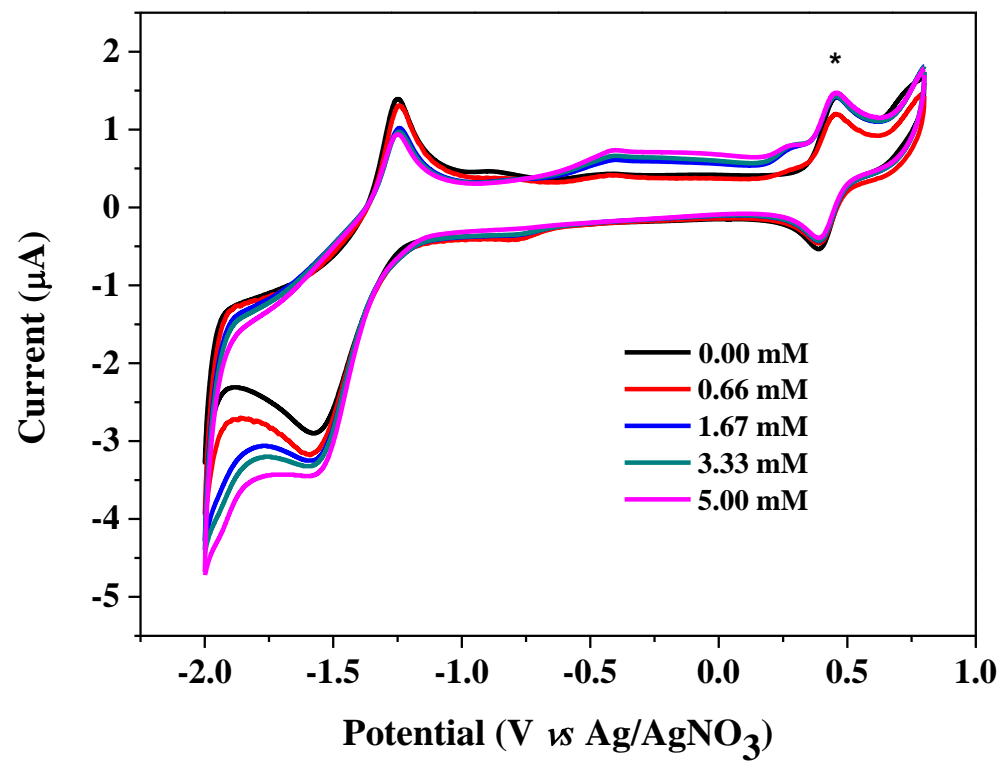

Fig. 5. $\mathrm{CVs}$ of a $2.94 \mathrm{mM}$ solution of complex 1 in $\mathrm{CH}_{3} \mathrm{CN}$ with varying concentrations of acetic acid. Conditions: $0.10 \mathrm{M}\left[\mathrm{n}-\mathrm{Bu}_{4} \mathrm{~N}\right] \mathrm{ClO}_{4}$ as supporting electrolyte, scan rate: $100 \mathrm{mV} / \mathrm{s}$, glassy carbon working electrode (1 mm diameter), $\mathrm{Pt}$ counter electrode, $\mathrm{Ag} / \mathrm{AgNO}_{3}$ reference electrode, $\mathrm{Fc}$ internal standard (*). 

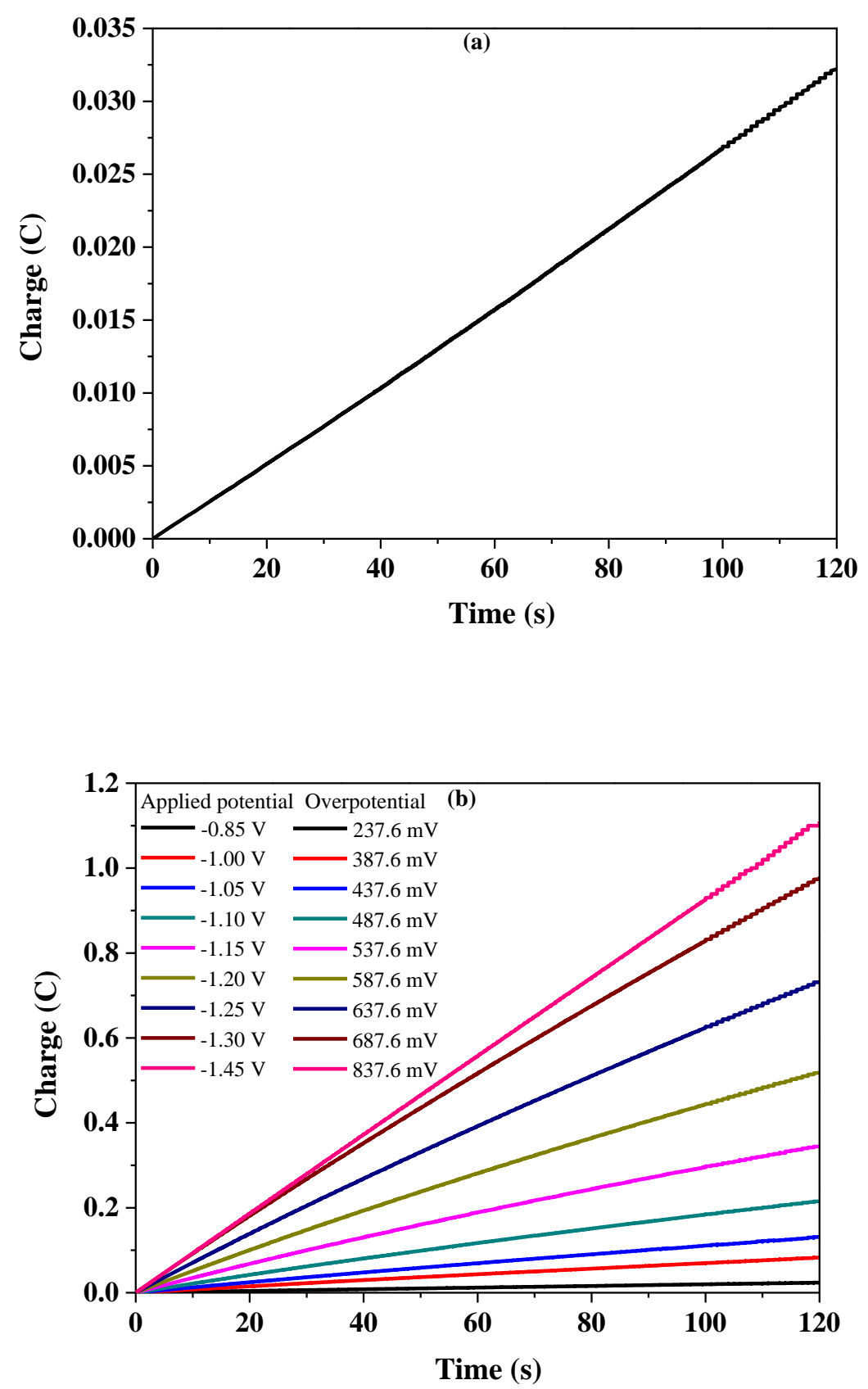

Fig. 6. (a) Charge buildup versus time from electrolysis of a $0.25 \mathrm{M}$ buffer solution ( $\mathrm{pH}$ 7.0) under $-1.45 \mathrm{~V}$ versus $\mathrm{Ag} / \mathrm{AgCl}$. (b) Charge buildup versus time from electrolysis of $6.67 \mu \mathrm{M}$ complex 1 under various applied potentials at pH 7.0. All data have been deducted blank. 


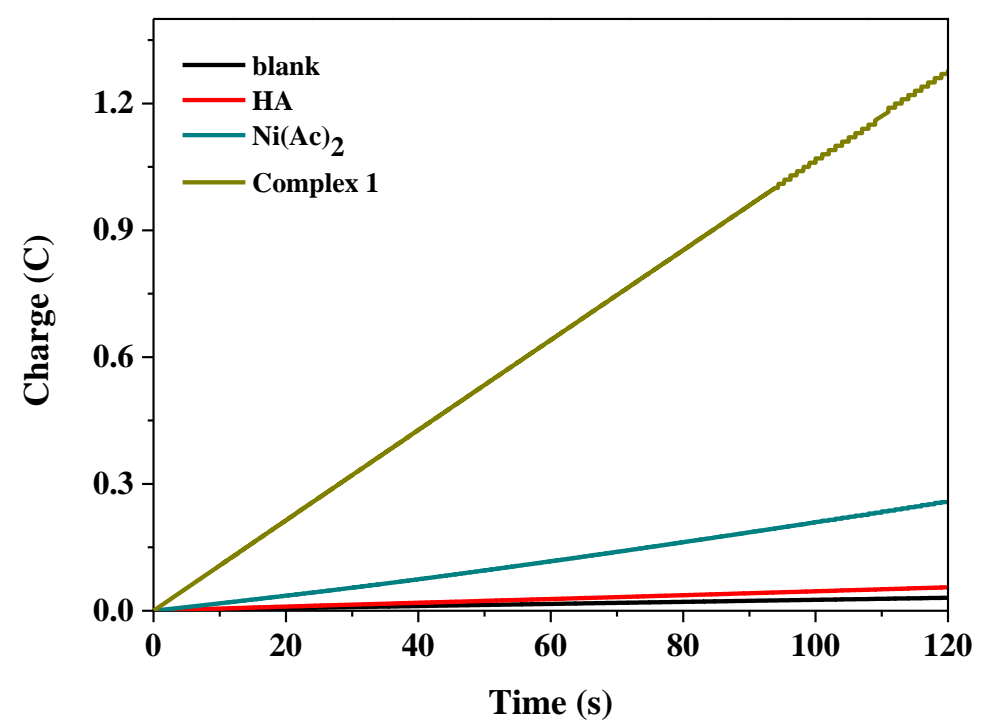

Fig. 7. Charge buildups versus time from the related components: blank (black), 5.34 $\mu \mathrm{M}$ HA (red), $5.34 \mu \mathrm{M} \mathrm{Ni(Ac)} 2$ (green) and $5.34 \mu \mathrm{M}$ complex 1 (yellow) under $-1.45 \mathrm{~V}$ versus $\mathrm{Ag} / \mathrm{AgCl}$ in a $0.25 \mathrm{M}$ buffer (pH 7.0). 